\title{
Analysis of heavy neurofilament subunit gene polymorphism in Russian patients with sporadic motor neuron disease (MND)
}

\author{
Veronika Skvortsova $^{1}$, Marya Shadrina*,2, Petr Slominsky ${ }^{2}$, Gleb Levitsky ${ }^{1}$, \\ Ekaterina Kondratieva $^{2}$, Anna Zherebtsova ${ }^{2}$, Nina Levitskaya ${ }^{1}$, Alexander Alekhin ${ }^{1}$, \\ Anna Serdyuk ${ }^{1}$ and Svetlana Limborska ${ }^{2}$
}

\footnotetext{
${ }^{1}$ Department of Fundamental and Clinical Neurology, Russian State Medical University, Lenskay str.15, block 3, Moscow, Russia; ${ }^{2}$ Institute of Molecular Genetics, Russian Scientific Academy, Moscow, Russia
}

Motor neuron disease (MND) results in the selective degeneration of motor neurons in the cerebral cortex, brain stem and spinal cord. The most common form of MND is amyotrophic lateral sclerosis (ALS). MND is complex and many genetic systems may be involved in the pathogenesis of this disease. Pathological and animal studies implicate neurofilament involvement in MND. The heavy subunit (NEFH) tail domain contains a repeated motif. In humans, there are two common variants: the $\mathbf{4 5}$ motif repeats long allele (L) and 44 motif repeats short allele (S). Previous studies have shown that the NEFH tail may be involved in the pathogenesis of MND. To investigate whether the L/S genotypes of the NEFH gene are associated with MND, we studied the frequency of $L$ and $S$ alleles in sporadic MND patients and a control population from Moscow. We observed a difference in SS genotype frequency between the control population and sporadic MND patients from Moscow. It was established that the SS genotype is sufficiently higher in sporadic MND patients. Moreover, we determined that patients with the SS genotype have the highest value of loss of the total clinical score. In summary, we conclude that the NEFH gene is involved in the pathogenesis of sporadic MND. The SS genotype represents a risk factor for the development and progression of sporadic MND in the Moscow population.

European Journal of Human Genetics (2004) 12, $241-244$. doi:10.1038/sj.ejhg.5201144

Published online 14 January 2004

Keywords: motor neuron disease; heavy neurofilament subunit gene; $L \backslash S$ polymorphism

Introduction

Motor neuron disease (MND) results in the selective degeneration of motor neurons of the cerebral cortex, brain stem and spinal cord. ${ }^{1}$ The most common form of MND is amyotrophic lateral sclerosis (ALS). At present, the cause of MND remains unknown. In some cases, the

*Correspondence: Dr M Shadrina, Institute of Molecular Genetics, Russian Scientific Academy, Kurchatov sq.2, Moscow 123 182, Russia.

Tel: + 7095 1960210; Fax: + 7095 1960221;

E-mail: shadrina@img.ras.ru

Received 25 April 2003; revised 10 November 2003; accepted 14 November 2003 disease is inherited, often as a dominant trait. Epidemiological studies in different populations show a $5-10 \%$ incidence of familial MND. The clinical and pathological features of familial and sporadic MND are virtually identical. Mutations in CuZn-superoxide dismutase gene (CuZn-SOD) gene have been found in 20\% of familial MND cases and a few per cent of apparently sporadic MND cases. $^{2,3}$ However, MND is a complex disease and other genetic systems may be involved in the pathogenesis of this disease.

Autopsy studies performed on MND sufferers have revealed aggregation and abnormal assembly of neurofilaments (NF) in the perikarya and proximal axon of the 
motor neurons. ${ }^{4}$ There are three NF subunits of light, medium and heavy molecular weight: NEFL, NEFM and NEFH. NEFM and NEFH have a tail domain that contains a repeated motif, $\mathrm{X}$-lysine-serine-proline- $\mathrm{Y}-$ lysine, where $\mathrm{X}$ is a single amino acid and $\mathrm{Y}$ is one to three amino acids. In humans, there are two common variants of the NEFH tail, one with 45 motif repeats, called the long (L) allele, and another with 44 repeats, termed the short (S) allele. $^{5}$

Various deletions of the NEFH tail have been revealed in MND patients. All cases of deletions in the $\mathrm{L}$ allele were associated with the disease; however, no association between deletions in the $\mathrm{S}$ allele and MND has been reported. Another study of familial and sporadic MND revealed no deletions in the NEFH gene, but described point mutations in patients and control subjects. ${ }^{6,7}$ These findings suggest a possible role of the NEFH gene in MND pathogenesis. To investigate whether the L/S genotypes of the NEFH gene are associated with MND, we studied the frequency of $\mathrm{L}$ and $\mathrm{S}$ alleles in sporadic MND patients and a control population from Moscow.

\section{Materials and methods}

With informed consent, blood samples were drawn from 62 Russian patients (36 female and 26 male PATIENTS) aged 29-73 years (mean $\pm \mathrm{SD}=55.1 \pm 10.7$ years) with apparently sporadic MND. All patients were seen at the Department of Fundamental and Clinical Neurology of Russian State Medical University, Moscow, and fulfilled the Revised E1 Escorial criteria for ALS/MND. ${ }^{8}$ A total of 49 patients (79\%) had ALS and 13 patients had progressive bulbar palsy (21\%). Patients were assessed by the Norris ALS Score ${ }^{9}$ every 6 months. The loss of total clinical score was calculated for the first year since onset. The control group included 50 randomly sampled individuals from Moscow. They were unrelated, neurologically normal and matched by age, sex and ethnicity. DNA was extracted from peripheral leukocytes by standard methods. ${ }^{10}$ Primers and conditions for PCR amplification was described early. ${ }^{11}$ One of the primers was labelled with $\left[{ }^{33} \mathrm{P}\right] \gamma \mathrm{ATP}$ before being used in the PCR reaction. Labelling reactions were performed in $20 \mu \mathrm{l}$ buffer, containing $2 \mu \mathrm{l} 10 \times$ kinase buffer, $50 \mathrm{pmol}$ of appropriate primer, $50 \mu \mathrm{Ci}\left[{ }^{33} \mathrm{P}\right] \gamma \mathrm{ATP}$ and $2.5 \mathrm{U}$ T4 polynucleotide kinase (Sileks, Russia). The PCR product was electrophoresed on an $8 \%$ nondenaturing polyacrylamide gel containing $0.5 \times$ TBE buffer. After electrophoresis, the gel was autoradiographed overnight. Analysis of Ala9Val polymorphism of Mn-SOD gene, of M235T polymorphism of ANG gene and of Ins/Del polymorphism of ACE gene was carried out as described. ${ }^{12-14}$

Statistical analysis was performed using Statistica v. 6.0 software.

\section{Results}

The results of the NEFH genotyping are presented in Table 1 . It is necessary to note that we only identified $L$ and $\mathrm{S}$ alleles, and did not reveal any deletions in the $\mathrm{L}$ and $\mathrm{S}$ alleles. As shown in the first two lines of Table 1, the $\mathrm{L}$ alleles had a higher (63\%) and S alleles had a lower (37\%) frequency in the control group. In patients, the frequency of the L alleles was $49.2 \%$ and that of the $\mathrm{S}$ alleles was $50.8 \%$. The comparative allele distributions carried out with the standard $\chi^{2}$ test revealed statistically significant divergences between the patients and controls $\left(\chi^{2}=4.27\right)$.

The last three lines of Table 1 demonstrate the genotype distribution for patients and controls. We identified 20 patients with the LL genotype, 21 with the LS genotype and 21 with the SS genotype. In the control group, there were $16 \mathrm{LL}, 31 \mathrm{LS}$ and 3 SS genotypes. The genotype distributions in both groups did not deviate from the Hardy-Weinberg equilibrium. The SS genotype frequency was significantly higher in patients (33.9\%) compared with the control group $(6.7 \%)$. Statistical estimation by the standard $\chi^{2}$ test of the difference in the SS genotype frequency between these groups gave the most significant results $\left(\chi^{2}=11,93\right.$ and $\left.P<0.001\right)$.

On the other hand, the distribution of the alleles of the Ala9Val polymorphism in Mn-SOD gene (Table 2), of the İ235Ò polymorphism in $\mathrm{ANG}$ gene and of $\mathrm{I} \backslash \mathrm{D}$ polymorphism of ACE gene did not differ from the control group (findings are not adduced), which is indicative of the absence of population stratification.

Table 1 Distributions of the NEFH genotypes and allele variants in MND patients and the control group from Moscow

\begin{tabular}{|c|c|c|c|c|c|c|}
\hline & \multicolumn{2}{|c|}{ MND patients } & \multicolumn{2}{|r|}{ Control } & \multirow[b]{2}{*}{$\chi^{2}$} & \multirow[b]{2}{*}{$P$} \\
\hline & $N$ & Frequency (\%) & $N$ & Frequency (\%) & & \\
\hline $\mathrm{L}$ & 61 & 49.2 & 63 & 63 & 4.27 & $P<0.05$ \\
\hline$S$ & 63 & 50.8 & 37 & 37 & & \\
\hline LL & 20 & 32.2 & 16 & 31.1 & 0.015 & NS \\
\hline$S L$ & 21 & 33.9 & 31 & 62.2 & 8.91 & $P<0.01$ \\
\hline SS & 21 & 33.9 & 3 & 6.7 & 11.93 & $P<0.001$ \\
\hline
\end{tabular}

Table 2 Analysis of Ala9Val polymorphism of Mn-SOD gene in MND patients and the control group from Moscow

\begin{tabular}{lcclccccc}
\hline & \multicolumn{2}{c}{ MND patients } & & \multicolumn{3}{c}{ Control } & & \\
\cline { 2 - 3 } & $N$ & Frequency (\%) & & $N$ & Frequency (\%) & $\chi^{2}$ & $P$ \\
\hline Ala & 57 & 46 & & 45 & 45 & 0.022 & NS \\
Val & 67 & 54 & & 55 & 55 & & \\
Ala/Ala & 13 & 21 & & 9 & 18 & 0.16 & NS \\
Ala/Val & 31 & 50 & & 27 & 54 & 0.18 & NS \\
Val/Val & 18 & 29 & & 14 & 28 & 0.013 & NS \\
\hline
\end{tabular}




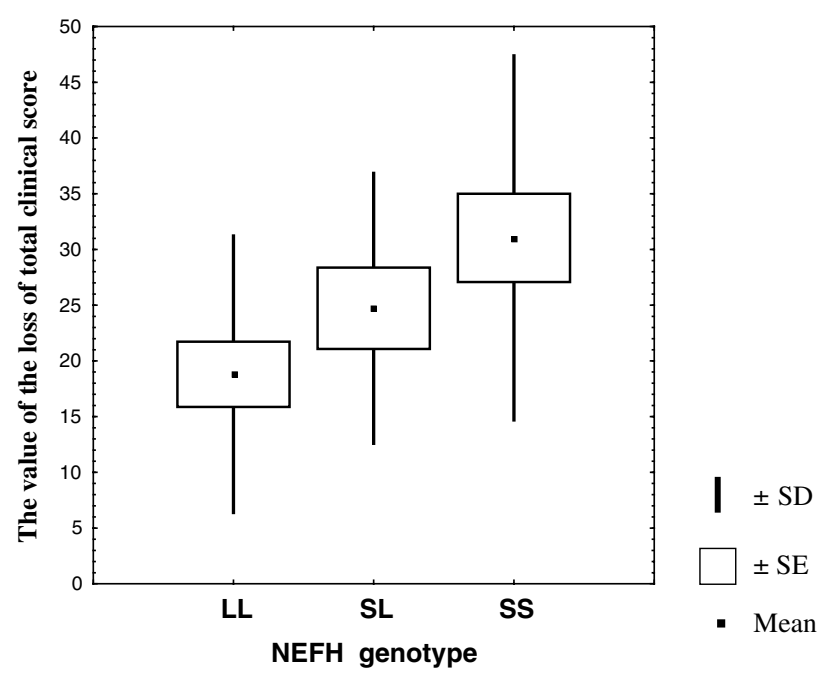

Figure 1 First year loss of the total clinical score (mean $\pm S D$ ) according to Norris Scale in MND patients with LL, LS and SS genotypes.

Figure 1 illustrates how the loss of the total clinical score was distributed between patients with LL, LS and SS genotypes. A statistically significant correlation was established between the loss of total clinical score and the NEFH genotypes (Spearmen correlation, $R=0.335, P<0.03$ ). The lowest values of loss of the total clinical score were observed in patients with the LL genotype (mean $\pm \mathrm{SD}$, $18.8 \pm 12.4$ ), and the highest values of total clinical score were observed in patients with the SS genotype (mean $\pm S D$, $31.1 \pm 16.3)$. The dissimilarity in the mean values of loss of the total clinical score in the patients with LL and SS genotypes was statistically significant (Newman-Keuls test $q=3.671, P<0.05)$.

\section{Discussion}

The potential importance of NF is underscored by the observation that abnormal accumulation of NF occurs in familial MND patients with various mutations in CuZnSOD. ${ }^{15,16}$ Moreover, transgenic mice with point mutations of the light NF rod, overexpression of human heavy NF or overexpression of mouse light NF all develop motor neuron pathology. Also, transgenic mice carrying CuZnSOD mutants develop NF accumulation. ${ }^{17,18}$

In this study, we investigated whether the $\mathrm{L}$ and $\mathrm{S}$ genotypes of the NEFH gene are associated with MND. We found a difference in SS genotype frequency between the control population and patients with sporadic MND. The SS genotype was significantly higher in these patients. These data suggest that the $\mathrm{S}$ genotype of the NEFH gene is involved in the pathogenesis of sporadic MND in the patients from Moscow. Moreover, patients with the SS genotypes had the highest values of loss of the total clinical score. The observed divergences are not connected with the stratification of the compared cohorts, as we failed to reveal any differences in the spectra of the allelic variants of Mn-SOD gene (which is probably involved in MND pathogenesis), ANG gene and ACE gene (genes of two proteins of rennin-angiotensine system, which have not been reported to partake in MND pathogenesis). In general, the distribution of $S \backslash \mathrm{L}$ polymorphism of NEFH gene in the random cohort from the Moscow population and in the random cohort from the Canadian population demonstrated quite a resemblance. ${ }^{5}$

However, Al-Chalabi et al ${ }^{6}$ analyzed the L/S genotypes of the NEFH gene in ALS patients from Scandinavia and UK and found no association. ${ }^{6}$ Thus, the influence of the polymorphism on the risk of MND development might be specific to Slavonic background.

To summarize, we conclude that the NEFH gene is involved in the pathogenesis of sporadic MND and that the SS genotype could be a risk factor for the development and progression of sporadic MND in the Russian population. Such an influence of heavy neurofilament subunit variants with different number of KSP repeats may occur due to peculiarities of phosphorylation of the $\mathrm{L}$ and the $\mathrm{S}$ isoforms of neurofilaments. That may in turn lead to disruption of neurofilament transport due to increased pausing in neurofilament movement, which may contribute to motoneuron death. ${ }^{19}$

\section{Acknowledgements}

This study was supported in part by a grant of the Russian Basic Research Foundation (Grant 02-04-48996), Russian Academy of Sciences program 'From basic sciences to medicine' and 'Physical and Chemical Biology', Russian State program 'Genotherapy and genodiagnostics'.

\section{References}

1 Nelson LM: Epidemiology of ALS. Clin Neurosci 1995; 3: 327-331.

2 Rosen DR, Siddique T, Patterson D et al: Mutation in CuZnsuperoxide dismutase gene are associated with familial amyotrophic lateral sclerosis. Nature 1993; 362: 59-62.

3 Scvortsova VI, Limborska PA, Slominsky PA et al: Sporadic ALS associated with the D90A CuZn-superoxide dismutase mutation in Russia. Eur J Neurol 2001; 8: 167-172.

4 Hirano A: Cytopathology of amyotrophic lateral sclerosis. $A d v$ Neurol 1991; 56: 91-101.

5 Figlewicz DA, Rouleau GA, Krizus A, Julien JP: Polymorphism in the multi-phosphorylation domain of the human neurofilament heavy-subunit-encoding gene. Gene 1993; 132: 297-300.

6 Al-Chalabi Am, Andersen PM, Nilsson P et al: Deletions of neurofilament subunit tail in amyotrophic lateral sclerosis. Hum Mol Genet 1999; 8: 157-164.

7 Julien J: Amyotrophic lateral sclerosis: unfolding the toxicity of the misfolded. Cell 2001; 104: 581-591.

8 Brooks BR, Miller RG, Swash M, Munsat TL, Airlie House 'Current Issues in ALS Therapeutic Trials' Workshop Contributors: E1 Escorial revisted: revised criteria for the diagnosis of amyotrophic lateral sclerosis (1998), (The WFN/ALS Website).

9 Norris FH, Callachini PR, Fallat RG et al: Administration of guanidine in amyotrophic lateral sclerosis. Neurology 1974; 24: $721-728$. 
10 Miller SA, Dykes DD, Polesky HF: A sample salting out procedure for extracting DNA from human nucleated cells. Nucleic Acid Res 1988; 16: 1215.

11 Figlewicz DA, Krizus A, Martinoli MG et al: Variants of the heavy neurofilament subunit are association with the development of amyotrophic lateral sclerosis. Hum Mol Genet 1994; 3: $1757-1761$.

12 Grasbon-Frodl EM, Kosel S, Reiss $\mathrm{O}$ et al: Analysis of mitochondrial targeting sequence and coding region polymorphisms of the manganese superoxide dismutase gene in German Parkinson disease patients. Biochem Biophys Res Commun 1999; 255: 749-752.

13 Hingorany $\mathrm{AD}$, Sharma $\mathrm{P}$, Jia $\mathrm{H}$ et al: Blood pressure and the M235T polymorphism of the angiotensinogen gene. Hypertension 1996; 28: 907-911.

14 Rigat B, Hubert C, Corvol P et al: FPCR detection of the insertion/ deletion polymorphism of the human angiotensin converting enzyme gene (DCP1)(dipeptidyl carboxypeptidase 1). Nucleic Acids Res 1992; 20: 1433
15 Hirano A, Donnefeld H, Sasaki S, Nakano I: Fine structural observation of neurofilamentous changes in amyotrophic lateral sclerosis. J Neuropathol Exp Neurol 1984; 43: 471-480.

16 Shaw CE, Enayat ZE, Powell JF et al: Familial amyotrophic lateral sclerosis. Molecular pathology of patient with a SOD1 mutation. Neurology 1997; 49: 1612-1616.

17 Julien JP, Cote F, Collard JF: Mice overexpressing the human neurofilament heavy gene as model of ALS. Neurobiol Aging 1995; 16: 487-490.

$18 \mathrm{Xu} \mathrm{Z}$, Cork LS, Griffing FW, Cleveland DW: Increased expression of neurofilament subunit NF-L produces morphological alterations that resemble the pathology of human motor neuron disease. Cell 1993; 73: 23-33.

19 Al-Chalabi Am, Miller CCJ: Neurofilaments and neurological disease. BioEssays 2003; 24: 346-355.

(Supplementary information accompanies the paper on European Journal of Human Genetics website http://www.nature.com/EJHG). 